\title{
Development of Tower Crane Simulation System with Flexible Wire Rope
}

\author{
Xin Wang ${ }^{1, ~ a}$, Yu-lan Lv ${ }^{1, ~ b}$, Di Wu ${ }^{1, c}$ \\ ${ }^{1}$ School of Mechanical Engineering, Dalian University of Technology, \\ Dalian 116023, China \\ awangxbd21@163.com, ${ }^{b}$ Ivyulan2013@163.com, ‘wudi23893@sina.com
}

\begin{abstract}
Based on virtual reality technology, a simulation system for training and checking tower crane operator is developed. In Virtools, an interactive 3D (three-dimensional) visual working environment is built, where an operator can simulate visual tower crane's motion with real operating feeling. By Catenary theory, hoisting rope's mathematics equation is built, and its flexible and swing simulation are studied with the physical functions provided by Virtools. According to relative standards and rules, automatic check and evaluation system is established. Simulation case shows the reasonability of motion and collision, objective and logical evaluation in this system.
\end{abstract}

Keywords: tower crane; wire rope; catenary equation; training and checking; simulation

\section{Introduction}

Tower crane, one of the major construction equipments, is widely used. But accidents are often caused. So it is necessary to train the operator. However, Training and checking cost is high using a real tower crane. Therefore, a training and checking simulation system of tower crane become a new mode.

Tower crane simulation is developed worldwide. In [1], Modeling and optimization techniques are studied and simple. The visual system modeling technologies are analyzed and studied in [2], however the fine model and complex motion should be further studied. In [3], a dynamic model of tower crane based on ODE is developed combined with the physical characteristics of tower crane mechanics. For swing objects in [4], it is created using the physical module in Virtools. In [5], a tower crane kinetic model is established to analyze load swing characteristics. In [6], a relatively complete tower crane simulation system is developed, which can control the crane motion by handle and button. A preliminary plan of the tower crane installation and training system is presented in [7]. A multiplayer virtual training system is developed in [8], in which tower crane can realize virtual assembly. In [9], a 3D+ simulator with head wear equipment is developed, in which the visual scene can rotate followed the operator's head. 
From above, tower crane's mathematic analysis is extensively studied in product design. However it is needed studied deeply in virtual training and checking. So in this paper, a relatively complete tower crane training and checking simulation system is studied, such as its constitute, 3D modeling, swing and flexible rope simulation, examination, evaluation and so on.

\section{Simulation system design}

The simulation system consists of working host, six-DOF motion platform, STICKCO Gemini 3D projector, 3D stereo glasses, worktable seat and other related hardware equipments. The structure of the system is shown in Fig. 1, and the hardware equipments are shown in Fig. 2.

The software framework of the system is shown in Fig. 3, which consists of several parts, such as 3D modeling, real-time simulation, data processing and system functions realization. And the interfaces of hardware and software is developed, which can realize the human-computer interaction. The technology of 3Dmax is used to show the fidelity of 3D models. The swing characteristics of wire ropes and swing objects are implemented by the physical module in Virtools. Catenary theory is applied to realize the flexible simulation of the rope. In terms of security operations, various safety limits are established, such as the travelling limit, lifting limit, load limiter, etc. Physical attributes are given to scene models, thus real-time collision detection is realized. In addition to conventional control view, cab view and hook view are provided to improve the realistic operation, which is shown in Fig. 4. In terms of human-computer interaction, the tower crane, swing objects and environmental parameters can be set easily. The city, beach and mountain scenes can also be built and selected. Real-time information of the crane's status and a variety of action messages are played on line. Assessment and evaluation system is established. The trajectory of swing objects is provided to evaluate the standardability and accuracy of the operator's action objectively. 

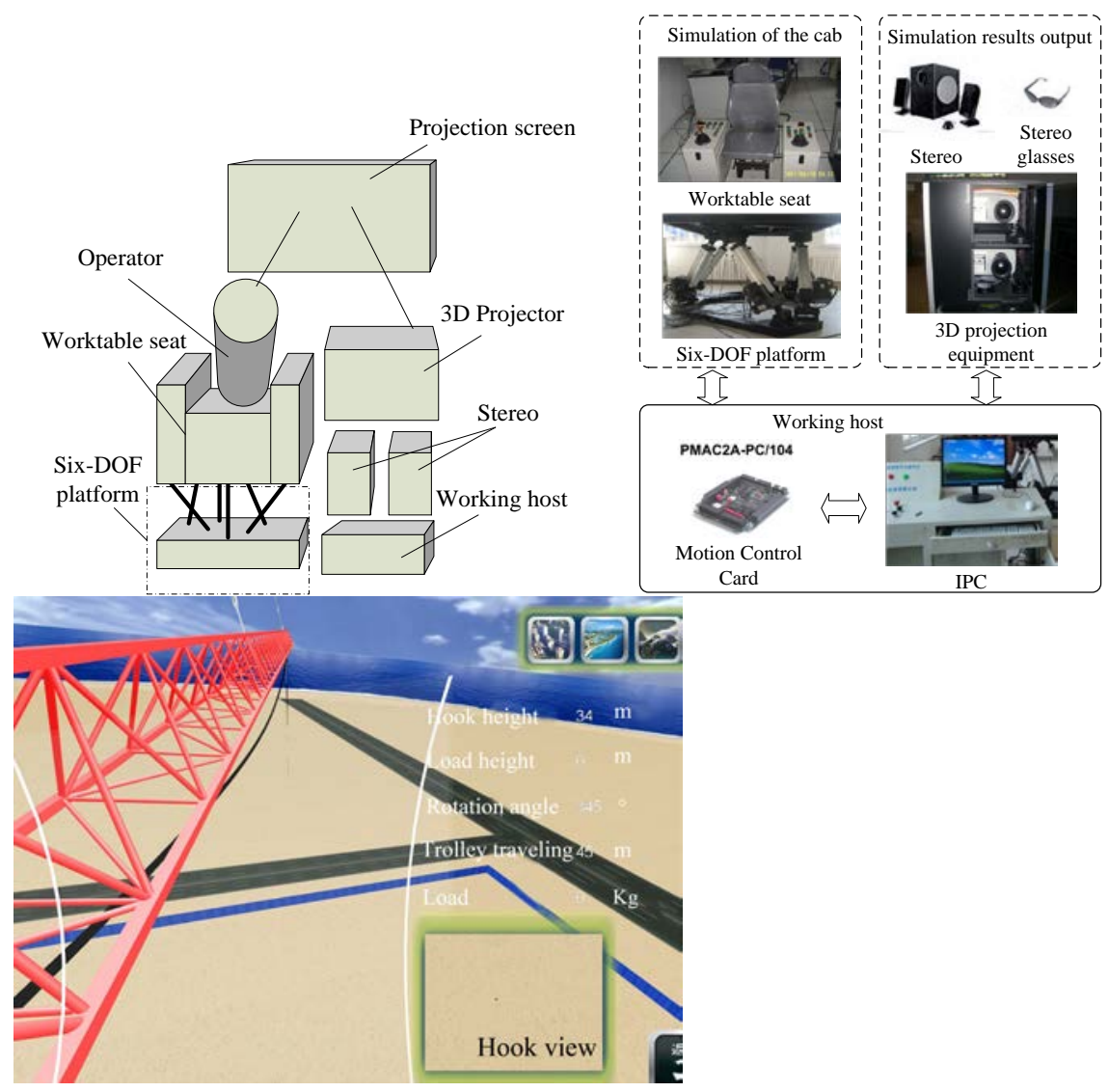

Fig.1 Structure of the system

Fig.2 Hardware equipments of the system

Fig. 4 Cab view and hook view 


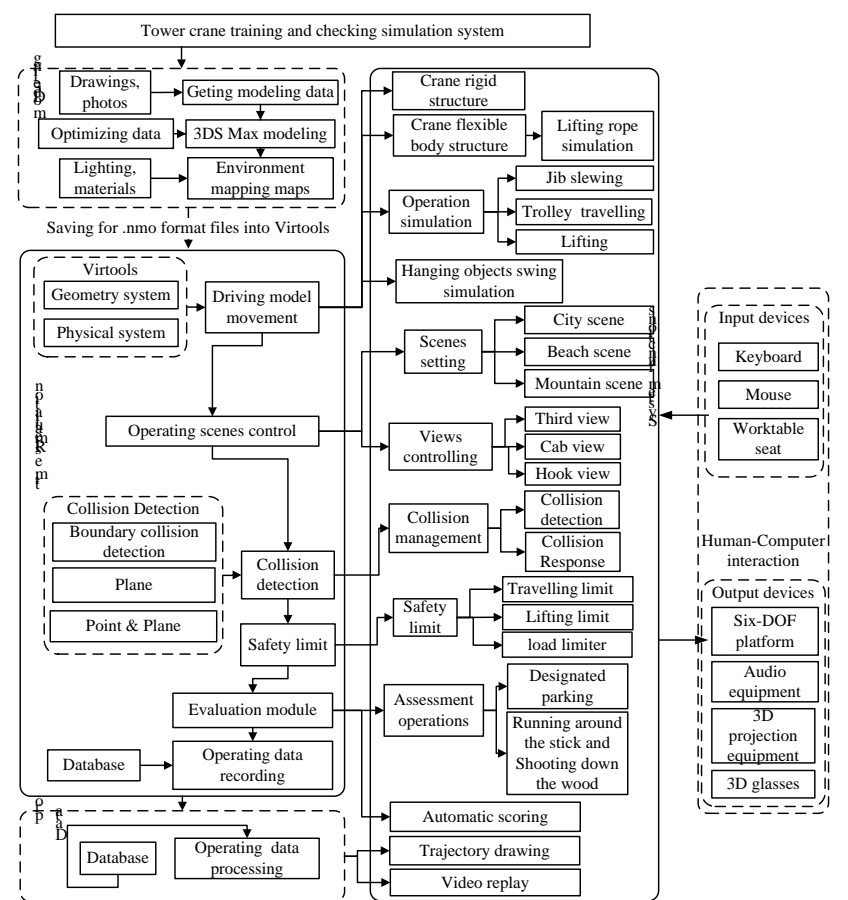

Fig. 3 Software framework of the system

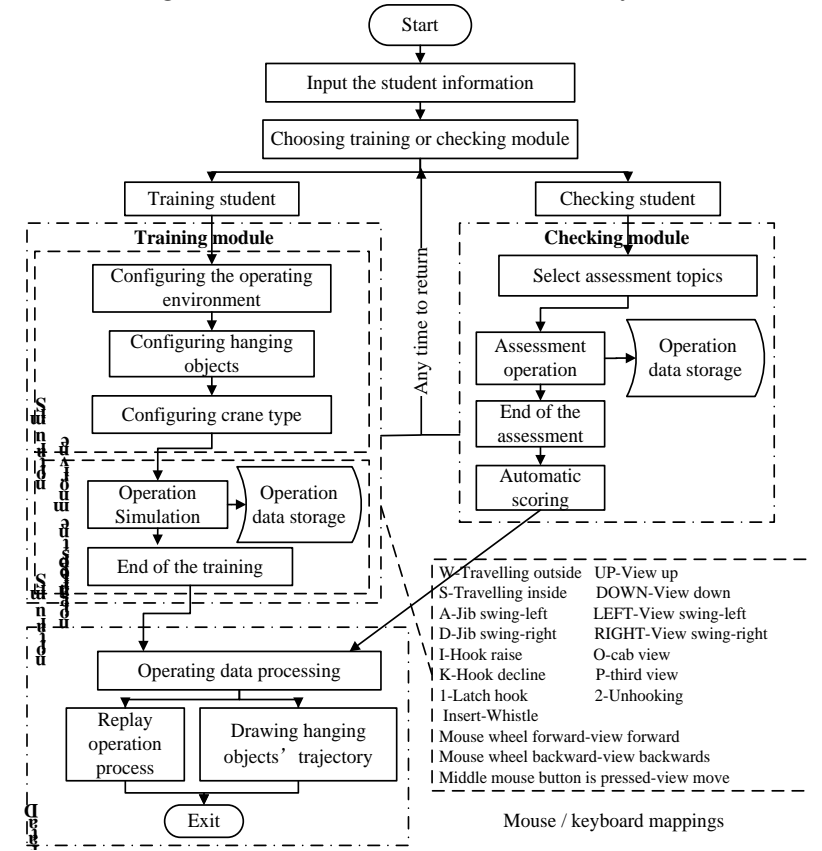

Fig. 5 Operating flowchart of the system 
Operating flowchart of the system is shown in Fig. 5. Wearing 3D glasses and sitting in the cab seat, the operator interacts with the simulation system by worktable seat (keyboard or mouse). Operator controls the motion of the tower crane model in the system, feeling the real-time response of the six-DOF platform's vibration just like that on a real tower crane.

\section{Flexible modeling and simulation of wire rope}

The structure of tower crane is rigid, its motion is also rigid. But, the wire rope is flexible due to its large slender proportion, especially more obviously without load, which causes the objects swing. So, catenary theory is applied to express the flexibility of wire rope, and physical module in Virtools is used to show the swing objects.

Before calculating the flexibility of rope, some assumptions are set: a) Only axial tension is applied to the rope without pressure and moment. b) The rope works within linear elastic scope. c) The weight of rope is evenly distributed.

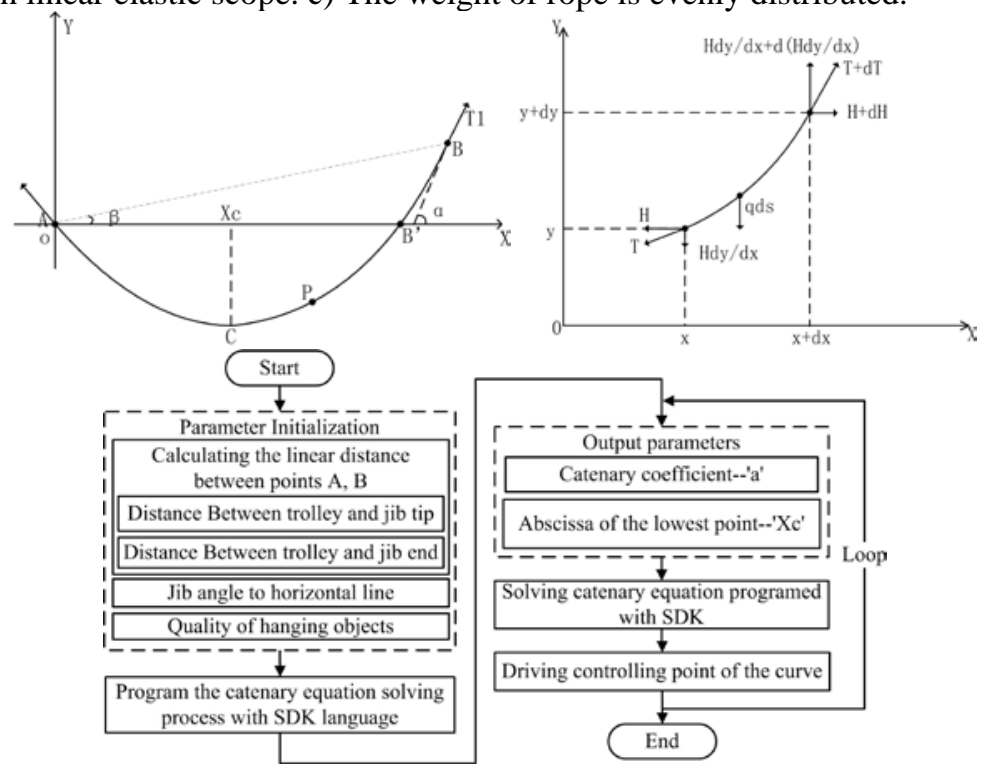

a) Principle of catenary $\quad$ b) Analysis of infinitesimal segment

Fig. 6 Mechanical analysis based on catenary theory Fig. 7 Flowchart of catenary calculation in Virtools

The mechanical analysis of rope is shown in Fig. 6, then the catenary equations of rope can be obtained as follow: 


$$
\left\{\begin{array}{l}
a=\frac{\lambda \cdot g}{H} \\
H=T_{1} \cdot \cos \alpha \\
y_{B}=\tan \beta \cdot x_{B} \\
y_{B}=\frac{1}{a} \cdot\left[\cosh \left(a \cdot x_{B}-a \cdot x_{C}\right)-\cosh \left(a \cdot x_{C}\right)\right] \\
\tan \alpha=\sinh \left(a \cdot x_{B}-a \cdot x_{C}\right)
\end{array}\right.
$$

Where $\lambda$ is linear density of the rope $(\mathrm{kg} / \mathrm{m})$, and $g$ is gravitational acceleration $\left(\mathrm{m} / \mathrm{s}^{2}\right)$. H is horizontal component of the infinitesimal segment tension $\mathrm{T}(\mathrm{N})$. $\beta$ is jib angle to horizontal line. The equation set is transcendental ones, which is solved by numerical approximation method.

The real-time display of the rope is completed using relevant BB (Building Blocks) of 3D Transformations / Curve Module in Virtools. The flowchart is shown in Fig. 7. For example, if the trolley working radius is 45 meters and the load is $1 \mathrm{t}$, the simulation results are shown in Fig. 8, which is obviously shows the flexibility of rope both with no-load and load.

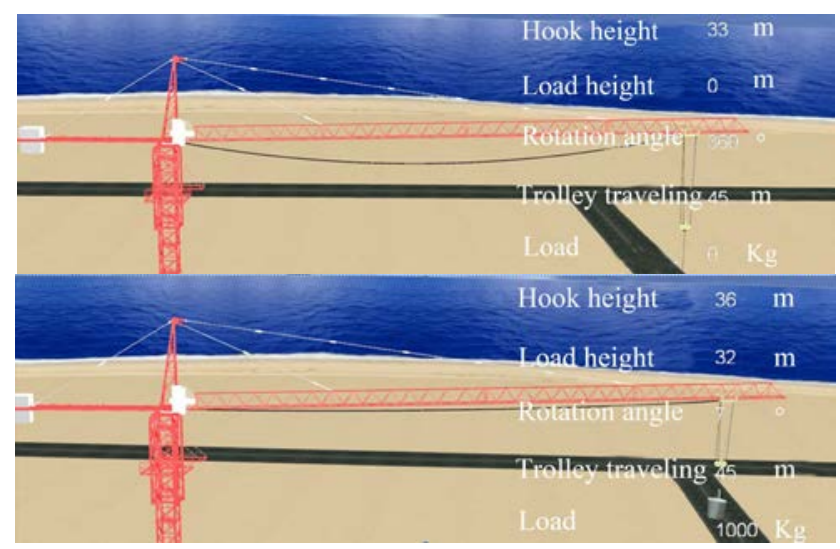

a) The simulation with load

b) The simulation without load

Fig. 8 The simulation with flexible rope

\section{Assessment system simulation}

The assessment methods, assessment time and assessment scoring standard of this system is built based on relevant rules ${ }^{[10]}$. Two assessment contents are set up based on the assessment standard, as shown in Table 1. 
Table 1 Evaluation standard of designated parking, running around the stick and shoot down the wood

\begin{tabular}{|c|c|c|c|c|c|}
\hline \multicolumn{3}{|c|}{ Evaluation standard of designated landing } & \multicolumn{3}{|c|}{$\begin{array}{c}\text { Evaluation standard of running around the stick and shoot down } \\
\text { the wood }\end{array}$} \\
\hline No. & Deductions project & Deduction & No & Deductions project & Deduction \\
\hline 1 & No checked, no whistle before driving & 3 & 1 & No checked, no whistle before driving & 3 \\
\hline 2 & Bucket out of the inner ring(D1) & 2 & 2 & Hit the stick once & 2 \\
\hline 3 & Bucket out of the middle ring(D2) & 4 & 3 & Knocked down the stick once & 3 \\
\hline 4 & Bucket out of the outer ring(D3) & 6 & 4 & Hit the pillar once & 3 \\
\hline 5 & Watering once & $1-3$ & 5 & Not shoot down wood once & 3 \\
\hline 6 & $\begin{array}{c}\text { Every ten seconds over a specified } \\
\text { time }\end{array}$ & 1 & 6 & Every ten seconds over a specified time & 1 \\
\hline 7 & Violation of rules or standards & 40 & 7 & Violation of rules or standards & 40 \\
\hline
\end{tabular}

Due to rope's flexibility, the bucket's is swinging during simulation, and its swing amplitude and frequency are changed with the operator's working speed. In simulation, one of key problems is collision detection and judge if the collided stick lies down or not. The solved method is to set physical characteristics of bucket and sticks by using the physical module in Virtools. The trajectory of the operating is recorded during the simulation. If the operation without following rules, the scores will be deducted, such as pause over two times during descending load.

\section{Case study}

It is taken the item of designated landing as a simulation case. Firstly, the information of an operator is input. Secondly, this item is selected and the timer starts to work. Operator should complete appropriate action in time. The trajectory of bucket is automatically displayed after the assessment, as shown in Fig. 9. Finally, evaluation scores are given by judging the standardability and accuracy of the operator's action according to relevant standard, as is shown in Fig. 10.

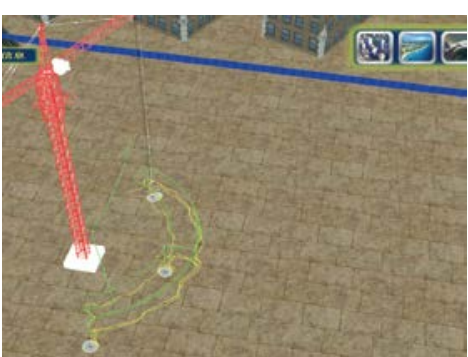

Fig. 9 Display of the trajectory of the bucket

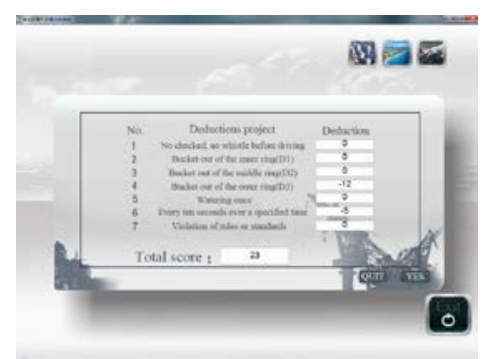

Fig. 10 Evaluation results 


\section{Conclusions}

The proposed simulation system for tower crane consists of cab worktable seat, 3D projection equipment, stereos and other hardware equipments. Catenary theory and physical system are applied to simulate the flexibility of rope and swing characteristics of objects, and to provide high-immersion operating environment. Evaluation subsystem is established based on assessment standard. Objective evaluation scores are given after simulation. Case shows the simulation system's authenticity, reasonability and efficiency. The future work will focus on the in-depth study of the real dynamic and feedbacks of the six degree of freedom platform.

\section{Acknowledgements}

This research is sponsored by the NSF of Liaoning Province (201102025) and Dalian STPP (2012A17GX122, 2013A16GX111), and Fundamental Research Funds for the Central Universities (DUT14ZD221).

\section{References}

[1] C.L. Zhu, M.X. Dong L.J. Qiu: Journal of Shandong Jianzhu University, Vol. 27(3) (2012), p. 284-288

[2] Z.B. Wang, C.R. Gao: Mechanical Engineering \& Automation, Vol. (1) (2008), p.37-39

[3] Z.M. Yang: Dissertation, Wuhan University of Technology. (2011)

[4] D.C. Chen: Dissertation, Shandong University. (2011)

[5] S.J. Xu, M.X. Dong, Z.J. Tuo: Hoisting and Conveying Machinery, Vol. (7) (2010), p. 17-19

[6] B. Ding, H.P. Liu, X.G. Shao: Manufacturing Automation, Vol. 34(10) (2012), p. $135-137$

[7] Q.N. Han, X.Y. Meng and F. Li: Hoisting and Conveying Machinery, Vol. (2) (2012), p. 49-52

[8] L. Heng, Greg Chan and Martin Skitmore: Journal of computer in civil engineering, Vol. 26(5) (2012), p. 638-647

[9] J.R. Juang, W.H. Hung, S.C. Kang: Advanced Engineering Informatics, Vol. 27(4) (2013), p. 506-518

[10] Crane Driver Safety Technology Assessment Criteria (GB6720-1986), 1986 